\title{
Opportunistic infection among HIV seropositive cases in Manipal Teaching Hospital, Pokhara, Nepal
}

\section{Dhungel BA ${ }^{1}$, Dhungel KU ${ }^{2}$, Easow $\mathrm{JM}^{3}$, Singh $\mathrm{YI}^{4}$}

${ }^{1}$ Lecturer, Department of Clinical Microbiology, ${ }^{2}$ Lecturer, Department of Clinical Physiology, Nepal Medical College, Attarkhel, Nepal, ${ }^{3}$ Assistant Professor, ${ }^{4}$ Professor, Department of Microbiology, Manipal College of Medical Sciences, Pokhara, Nepal

\begin{abstract}
Background: Human Immunodeficiency Virus (HIV)/ Acquired Immunodeficiency Syndrome (AIDS) claimed more than 22 million deaths in the past two decades. About 10,000-15,000 Nepalese are expected to die of AIDS related deaths every year in the absence of effective treatment and care. Major cause of mortality and morbidity in HIV infected people is opportunistic infection (OI). Type of pathogen(s) responsible for OI varies from region to region.

Objective: This study attempts to find out OI among HIV seropositive patients visiting MTH, Pokhara.

Results: Tuberculosis (30\%) was found to be most common OI followed by candidiasis (14\%). Pulmonary tuberculosis $(21.14 \%)$ was more common than extra pulmonary tuberculosis $(8.92 \%)$. Oral candidiasis $(8.92 \%)$ was more common than oesophageal candidiasis (5.35\%).

Conclusion: The study findings indicate that immediate and strong action needs to be taken and guidelines and strategies to tackle the HIV AIDS problems are required and should be equally implemented to achieve a decline in the rate of prevalence of HIV.
\end{abstract}

Key words: HIV, AIDS, Opportunistic infection, Tuberculosis

$\mathrm{H}^{\mathrm{u}}$ uman Immunodeficiency Virus (HIV)/ Acquired Immunodeficiency Syndrome (AIDS) has already infected more than forty million people worldwide and is continuing to spread at an alarming rate. ${ }^{1,2}$. All efforts are being made to fight HIV/AIDS. Studies on vaccine against HIV and effective treatment of HIV infection are going on in full pace. Two types of vaccines are under study, preventive vaccine for HIV negative individuals and therapeutic vaccine to improve the immune system of HIV positive patients ${ }^{3}$. Currently no HIV/AIDS vaccines are approved for use, though many are in clinical trial studies ${ }^{3}$. Neither has the spread of HIV stopped nor is the management of HIV cases satisfactory. The management of HIV/AIDS still looks a defiant task to humankind. The progress and outcome of HIV/AIDS is influenced by factors such as baseline health, nutritional status, environment, endemic diseases and access to therapy. It is important to understand the presentation of HIV diseases in the local context to minimize the HIV/AIDS related mortality ${ }^{4}$. Major causes of mortality and morbidity in HIV infected people is Opportunistic infection (OI). Type of pathogen responsible for OI varies from region to region. Therefore, identification of the specific pathogen(s) is important for management of such cases ${ }^{5}$. Limited studies are done regarding HIV related OI in Nepal hence present study was carried out $^{6,7,8,9,10,11}$.

\begin{abstract}
Materials and methods
Pertinent clinical examination of all the cases coming to Manipal Teaching Hospital, Pokhara, Nepal was carried out. Enzyme Linked Immunosorbent Assay (ELISA, Biokit Bioelisa HIV-1+2 (rec)) and spot test (HIV Tridot, J. Mitra \& Co. Ltd.) were used to screen the HIV suspected cases among those patients. HIV testing was done on the basis of clinical suspicion; chief complains of the patients being fever, chronic cough, chronic diarrhoea, weight loss and some patients had history of high risk behaviour as commercial sex workers/their clients and intravenous drug users. 54 HIV seropositive cases were recorded during the study period from March 2004 to September 2005. Clinical history, age, sex, occupation and relevant personal details of the HIV seropositive patients were recorded.
\end{abstract}

As per the symptoms and clinical presentation various samples such as sputum, cerebrospinal fluid (CSF),

\footnotetext{
Correspondence

Banodita Acharya Dhungel

Lecturer, Dept. of Clinical Microbiology,

Nepal Medical College Teaching Hospital,

Attarkhel, Nepal

E-mail: banodita@hotmail.com
} 
stool, oesophageal brushing, lymph node aspirate, blood and urine were collected for the diagnosis of OI. The samples were processed according to the different pathogens and OI suspected ${ }^{12}$. Necessary precautions were taken while collecting and processing the samples.

\section{Results}

During the study period from March 2004 to September 2005, 54 HIV seropositive cases were detected from a total of 681 suspected cases. These patients presented of various signs and symptoms like weight loss, loss of appetite, chronic diarrhoea, dysphagia, chronic cough etc. However some patients came for voluntary testing as well.
As per the symptoms and clinical presentations in HIV positive patients, different etiological agents causing opportunistic infections were identified as shown in Table 1. Tuberculosis (TB) was found to be the most common opportunistic infection $(30 \%)$ out of which $70 \%$ were pulmonary and $30 \%$ extra pulmonary tuberculosis (Fig 1), followed by oral candidiasis (9\%). Extra pulmonary TB included, central nervous system $(18 \%)$, pleural $(6 \%)$ and abdominal cavity $(6 \%)$. About eleven percents of the HIV seropositive patients were asymptomatic. Twenty-seven percent of cases were categorized as 'others', which included the patient whose health was deteriorating and also showed clinical signs and symptoms as nephropathy, hemiplagia, psychological disorder, lymphadenopathy etc (Fig 2).

Table 1: Distribution of Opportunistic infection in HIV seropositive patients.

\begin{tabular}{|l|c|}
\hline Opportunistic infection & Number of patients \\
\hline Tuberculosis & 17 \\
\hline Candidiasis & 8 \\
\hline Pneumocystis carinii pneumoniae & 2 \\
\hline Cryptosporidial infestation & 2 \\
\hline Disseminated Cryptococcosis & 1 \\
\hline Pneumococcal pneumonia & 1 \\
\hline Bacteremia & 1 \\
\hline Dermatophytoses & 1 \\
\hline Hepatitis & 2 \\
\hline Asymptomatic & 6 \\
\hline Others & 15 \\
\hline Total & $56^{*}$ \\
\hline
\end{tabular}

*: out of total 54 HIV seropositive patients two patients had polymicrobial infection

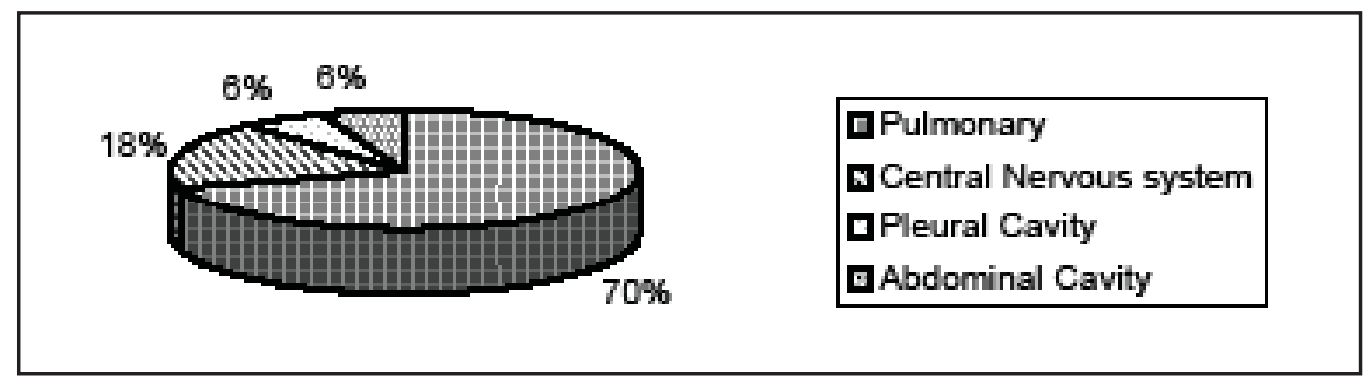

Fig 1: Distribution of tuberculosis in different body sites. 


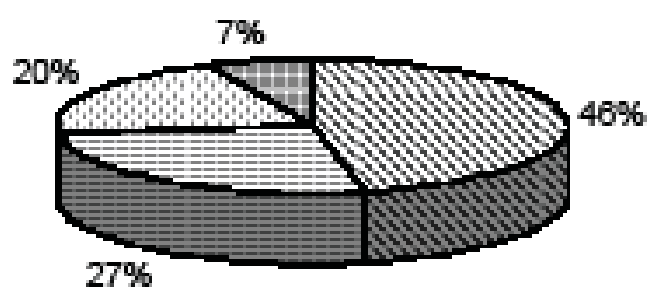

\section{- Subgroup A of group IV 口Subgroup E of group IV mGroup III 口Subgroup B of group IV}

Subgroup A of group IV: Chronic diarrhoea, Chronic coughs not due to opportunistic infection, unexplained weight loss not due to opportunistic infection, intermittent fever and sweats.

Subgroup B of group IV: Neurological disease.

Group III: Persistent generalized lymphadenopathy. Many HIV infected people develop generalized swelling of lymph nodes usually in the neck and underarms.

Subgroup E of group IV: Tumors, infectious or other conditions not listed in the above subgroups but which appears in relation to HIV infection.

Fig 2: Distribution of group "OTHERS" according to CDC classification.

\section{Discussion}

Progression of HIV infection is largely dependent on the interaction between the viral and host factors. HIV brings about the destruction of $\mathrm{CD}_{4}^{+}$lymphocytes, which are the crucial cells in forming immune response to foreign antigens and it is also the primary target cells of HIV ${ }^{13,14}$. The progressive loss of these lymphocytes eventually results in the loss of an ability to mount desirable immune response to any pathogen ${ }^{13}$ and death of the patients in the terminal stage of HIV infection occurs ${ }^{14}$. Major cause of morbidity and mortality of such patients are opportunistic infections ${ }^{15}$. In the present studies, majority of the opportunistic infection were reported in the age group 30-39 years (38\%). About four percents of the HIV seropositive patients had polymicrobial infections, which included oral candidiasis plus pulmonary tuberculosis in $2 \%$ and pneumococcal pneumonia plus cryptosporidial infestation in $2 \%$. All these patients belonged to the age group 30-39 years. It may be because the diagnosis of OI was made only on clinical signs and symptoms or when illness is quite advanced and by then it may be polymicrobial in nature ${ }^{16}$.

Present study showed that tuberculosis $(30 \%)$ is the most common opportunistic infections similar to the finding in Nepal and India ${ }^{6,11,17}$. From a total of $30 \%$ cases of tuberculosis, $70 \%$ were pulmonary tuberculosis in the present study. In a study done in Palpa, Nepal ${ }^{11}, 40 \%$ HIV seropositive cases were reported to have tuberculosis out of which $75 \%$ had pulmonary tuberculosis and $25 \%$ had extra pulmonary tuberculosis ${ }^{11}$. Among the large number of reports available, pulmonary tuberculosis is reported more than any other clinical forms in HIV/AIDS patients ${ }^{18,19,20}$. Seventeen million people in Africa and more than four million people in South Eastern Asian region (SEAR) were infected with both HIV and tuberculosis in $2000^{21}$. It is feared to be even more in the year 2006. Other major opportunistic infection in HIV positive patients, in the present study was oral candidiasis (9\%). In a study in South India, oral candidiasis was reported in 59\% of AIDS cases ${ }^{22}$. Candidiasis occurs frequently with HIV infection ${ }^{7,9}$. It has been reported that candidiasis occurs in up to $70 \%$ of HIV infected cases. ${ }^{4}$ Similar conclusions was obtained in one of the hospital based study in India, where the most common opportunistic infection in HIV infected cases is tuberculosis which is followed by candidiasis ${ }^{5}$.

In the present study $7 \%$ of HIV infected patients were also diagnosed to be suffering from meningitis due to Mycobacterium tuberculosis (5\%) and Cryptococcus $s p(2 \%)$. HIV coinfection with Cryptococcal sp has increased from $20 \%$ in $1992-1996$ to $37 \%$ in $1996-$ 2000 to $49 \%$ in $2000-2004$ at All Indian Institute of Medical Sciences (AIMS) 4 . About two percent of HIV seropositive cases of present study were co infected with Hepatitis B Virus (HBV), similarly $2 \%$ of the HIV seropositive patients were coinfected with Hepatitis C Virus (HCV). All the coinfected patients were intravenous drug users. All three viruses HIV, $\mathrm{HBV}$ and $\mathrm{HCV}$ share common mode of transmission 
and common risk groups 5 . Up to $90 \%$ of homosexual AIDS patients have markers of post or ongoing HBV infection $^{23}$. In one of the studies among Nepalese blood donors $^{24}$, HIV/HBsAg co prevalence was recorded in $0.033 \%$ cases. Higher co prevalence rate was reported in a study done in Delhi, India, 28\% of the HIV infected patients harbor HBV simultaneously in contrast to $2 \%$ among control ${ }^{25}$.

Two of the HIV seropositive patients were coinfected with Pneumocystis carinii pneumonia (PCP) in the present study. It is now established that PCP is one of the common opportunistic infections in $\mathrm{HIV}^{7}$ but the cases are relatively less documented, may be due to the lack of routine testing facility. PCP is rarely documented in India too $^{22}$. However, in a study in $\mathrm{Nepal}^{10}, 2$ out of of 13 HIV positive cases were found to have PCP. Eleven percents of HIV seropositive patients were asymptomatic in our study. These patients belong to Group II in Centre for Disease Control (CDC) classification of HIV infection. They remain well after seroconversion for many years before developing AIDS, but during this time they are infectious ${ }^{26}$. Twenty-one percents of the HIV seropositive patients were grouped as "others" in the present study. These patients presented clinical features of Group III and IV of CDC classification of HIV infection ${ }^{26}$. It includes those with AIDS or AIDS related complex (ARC). Among them 46\% belonged to Subgroup A, 7\% belonged to Subgroup B and 20\% belonged to Subgroup E of group IV and 27\% belonged to group III, CDC classification for HIV infection. (Fig 2)

As in the present study, pulmonary tuberculosis is the most common opportunistic infection in HIV seropositive patients in $\mathrm{Nepal}^{6,11}$ and India too ${ }^{17,27}$. This may be due to endemicity of the causative agent. However determining the spectrum of OIs and the changing pattern over the years, in a given region requires adequate surveillance and good diagnostic services that are not available in many parts of the developing countries like Nepal. OI as oral candidiasis that can be diagnosed with reasonable accuracy by physical examination or by inexpensive laboratory techniques may be documented more frequently than OI requiring more cumbersome procedures of collection and diagnosis as PCP, viruses ${ }^{4}$.

OI and reactivated latent infections seen in HIV infected persons will vary from region to region as OIs like Mycobacterium Avium Complex (MAC), Kaposi's sarcoma are frequently reported in the developed world ${ }^{28}$ where as tuberculosis is the most common OI in HIV positive patients in our context. This could be due to few environmental exposures, difference in host susceptibility, prevalence of particular pathogens in an environment, earlier death owing to exposure to more virulent organisms, diagnostic difficulties, paucity of experienced / trained personnel to look for these infections ${ }^{28}$.

By early 2005, more than 1800 cases of full blown AIDS were officially reported in Nepal and $0.5 \%$ of the adult population between the age of 15-49 years which is also the most prolific age group, are estimated to have HIV infection. In the absence of effective intervention, AIDS can be the leading cause of death in this age group, which would mean a colossal negative impact on country's social and economical development. The impact of HIV/AIDS would surely increase poverty and vulnerability ${ }^{29}$.

\section{Conclusion}

HIV/AIDS is the burning crisis worldwide. However, the approach for the management of the issue is dissimilar in different countries. In low prevalence countries like Nepal, USAID aims to deliver prevention activities while in high prevalence countries it is implementing a package that includes care and support activities. Nepal is signatory to the Millennium development goals, which has set year 2015 as target to be able to reversethe spread of HIV/AIDS ${ }^{29}$. The chances to achieve the goal looks very remote as the data from National Centre for AIDS and STD control (NCASC) shows that in August 2004 there were 4164 HIV positive cases including AIDS, in July 2005 the number increased to 5201, further it increased to 7373 in July 2006 and the figure reached 10546 by December $2007^{30}$. These fig suggest that Nepal still has a long way to go, immediate strong action to be taken, guidelines and strategy to tackle the HIV/AIDS problem to be strictly adhered to, so that the prevalence rate of HIV will decline.

\section{References}

1. Sharma S. HIV and AIDS: the global perspective and the challenges for Nepal. Kath Univ Med J. 2004; 2(8):283-5.

2. Reports on the global AIDS epidemic: Executive summary. A UNAIDS $10^{\text {th }}$ anniversary special edition. UNAIDS, 2005. [online]Available on http://data.unaids. org/pub/GlobalReport/2006/2006_GRExecutiveSummary_en.pdf

3. Vaccines, AIDSinfo.[online] avalilabe on http:// aidsinfo.nih.gov/vaccines

4. Kumarasamy N, Vallabhaneni S, Timothy P, Flanigan, Kenneth HM, Solomon S. Clinical Profile of HIV in India. Ind J Med Res. 2005; 121: 377-94.

5. Ayyagari A, Sharma AK, Prasad KN, Dhole TN, Kishore J, Chaudhary G. Spectrum of opportunistic infection in Human immunodeficiency virus (HIV) infected cases 
in tertiary care hospital. Ind J Med Microbiol. 1999; 17: 78-80.

6. Luitel BR, Lamgade A, Bhusal L, Napit I. Trends of HIV infection in united mission hospital Tansen: A retrospective glimpse. J Nep Med Assoc. 2005; 44:16.

7. Khadga P. Opportunistic infections related to HIV/AIDS. J Nep med Assoc. 2005; 44: 21.

8. Adhikari N, Rai SK, Singh A, Ghimire G, Choudhary DR. Prevalence of enteric parasitic infections among HIV positive subjects and AIDS patients in Nepal. Abstract in: Book of Abstracts, IX Congress of Asia Pacific Association of Societies of Pathologists (APASP) \& V Congress of Association of Clinical Pathologists of Nepal (ACPN), November 24-26, $2005: 54$

9. Dahal S, Rai SK, Ghimire P, Ghimire G, Choudhary DR. Prevalence of bacterial \& fungal agents causing lower respiratory tract infections in HIV infected individuals. Abstract in Book of Abstracts, IX Congress of Asia Pacific Association of Societies of Pathologists (APASP) \& V Congress of Association of Clinical Pathologists of Nepal (ACPN), November 24-26, $2005: 55$

10. Sapkota D, Ghimire P, Manandhar S. Enteric parasitosis in patients with Human Immunodeficiency Virus (HIV) infection \& Acquired Immunodeficiency Disease (AIDS) in Nepal. J of Nep Health Res Council. 2004;2 :9-13.

11. Napit IB. HIV status in United misson hospital, Tansen, Palpa. J of Nep Med Assoc. 2001; 40: 29-33.

12. Mackie, McCartney, Collee JG, Durgid JP, FraserAG, Marmion BP. Practical Medical Microbiology, $13^{\text {th }}$ ed, Singapore, Longman Singapore publishers (Pte) Ltd, 1989; 402

13. Pattanapanyasat $\mathrm{K}$, Thakur MR. $\mathrm{CD}_{4}+\mathrm{T}$ cell count as a tool to monitor HIV progression and antiretroviral therapy. Ind J Med Res. 2005; 121: 539-49.

14. Paranjape RS. Immunopathogenesis of HIV infection. Ind J Med Res 2005; 121: 240-55

15. Gordon JD, Timpone JG, Schnittman SM. Emergence of unusual opportunistic pathogens in AIDS; a review. Clin Infect Dis. 1992; 15 $: 134-57$.

16. Shailaja VV, Pai LA, Mathur DR, Lakshmi V. Prevalence of bacterial and fungal agents causing lower respiratory tract infection in patients with human immunodeficiency virus infection. Indian J Med Microbiol. 2004; 22: 28-33
17. Kumarasamy N, Solomon S, Flanigan TP, Hemalatha R, Thyagarajan SP, Mayer KH. Natural history of human immunodeficiency virus diseases in southern India. Clin Inf Dis. 2003; 36: 79-85.

18. Kumarasamy N, Solomon S, et al. Spectrum of opportunistic infections among AIDS patients in Tamil Nadu, India. Ind. J STD AIDS. 1995; 6: 447-9

19. Jain SK, Aggrawal JK, Rajpal I, Baveja U.Prevalence of HIV infection amongst tuberculosis patients in Delhi-A sentinel surveillance study. Ind J Tuber. 2000; 47: 21-6.

20. Arora VK, Gowrinath K, Rao RS. Extrapulmonary involvement in HIV with special reference to tuberculosis cases. Ind $\mathrm{J}$ Tuber. 1995; 42: 27-32.

21. Mohanty KC, Sundrani RA. HIV infection in patients with respiratory disease. Ind J Tuberc. 1993; 40: 5-12.

22. Singh A, Bairy I, Shivananda PG. Spectrum of Opportunistic infection in AIDS, Ind J of Med Sci. 2003; 57: 16-21

23. Banerjee U; Progress in diagnosis of opportunisitc infections in HIV/AIDS. Ind $\mathrm{J}$ Med Res. 2005; 121: 395-406.

24. Tiwari B.R., Ghimire P, Thapa D, Rajkarnikar M. Seroprevalence of Hepatitis B and HIV among Blood donors of Kathmandu, Nepal. Abstract in Book of Abstracts, IX Congress of Asia Pacific Association of Societies of Pathologists (APASP) \& V Congress of Association of Clinical Pathologists of Nepal (ACPN), November 24-26, 2005 :94

25. Baveja UK, Chattopadhya D, Khera R, Joshi PL. A cross sectional serological study of the coinfection of HBV, HCV and HIV amongst a cohort of IDUs at Delhi. Ind J Med Microbiol. 2003; 21: 280-83.

26. Cheesebrough M. HIV supplement. Medical laboratory manual for tropical countries. 3rd ed. Singapore, Longman Singapore publishers (Pte) Ltd, ELBS 2(Suppl): S1-S23, 1990.

27. Mirdha BR. Mycobacterium aviumintracellulare in stool in HIV-seropositive man. Ind J Gastroenterol. 2003; 22:5.

28. World Health Organization. Guidelines on Standard Operating Procedure for Laboratory Diagnosis of HIV-Opportunistic Infections. New Delhi. Ed Kumari S. 2001.

29. Millenium Development Goals: epal [online] Available on http://www.indexmundi.com/ nepal/millennium-development-goals.html

30. Cumulative HIV \& AIDS situation of Nepal. National Center for AIDS \& STD control, Teku, Kathmandu. (15, December,2007) 